\title{
Crianças multirrepetentes do Ensino Fundamental: o que pensam sobre seus contextos escolares*
}

\author{
Failured Elementary School children: what they think about their school contexts
}

Niños multirepetentes de la escuela primaria: lo que piensan acerca de sus contextos escolares

\author{
GABRIELA MAIA FISCHER** \\ VERÔNICA GESSER $* * *$
}

\begin{abstract}
RESUMO
Este trabalho se propôs a investigar as expectativas das crianças com histórico de reprovação em relação a aulas vivenciadas por elas nas séries iniciais do Ensino Fundamental. A pesquisa teve como objetivo identificar os significados do contexto escolar por meio das vozes de crianças multirrepetentes dos anos iniciais do Ensino Fundamental ( $2^{\mathrm{o}}$ a 4ㅇ ano). Autores como Patto (2008), Charlot (2009 e 2000), Vygotsky (1984, 2007); Ferreiro (1996), Lerner (2001), Solé e Coll (2004), Sampaio (2004), Sacristán (2000, 2007), dentre outros, fundamentaram teoricamente este trabalho. Para a realização da pesquisa, contou-se com a participação de oito crianças, de duas escolas distintas, matriculadas regularmente nas séries iniciais do Ensino Fundamental, sem comprometimento cognitivo com laudo, e que continham em seu histórico escolar pelo menos dois anos de reprovação. Os procedimentos de coleta de dados fundamentou-se em pesquisa de campo, desenvolvida por meio de duas entrevistas individuais semiestruturadas com cada sujeito participante (SZYMANSKI, 2002; GASKELL, 2010). E os dados das entrevistas foram interpretados, discutidos e apresentados a partir dos eixos temáticos gerados em três momentos de análise (LEFREVE, A. M. e LEFREVE, F., 2005; FLICK, 2009). O estudo permitiu observar que determinadas práticas metodológicas produziram nas crianças significados característicos de um ensino centrado na perspectiva reprodutivista, que, segundo as crianças da pesquisa, prioriza o volume de conteúdos, a cópia, e não valoriza o erro como parte inerente da aprendizagem.
\end{abstract}

Palavras-chave: Fracasso escolar. Crianças multirrepetentes. Metodologias de ensino. Ensino Fundamental.

\begin{abstract}
This study aimed to investigate on the expectations of children with disapproval history regarding lessons experienced by them in the early grades of Elementary School. The research aimed to identify the meanings of the school context through the voices of children multirepetentes Years of Elementary Education Initials (2 to 4 years). Authors such as Patto (2008), Charlot (2009 and 2000), Vygotsky (1984, 2007); Blacksmith (1996), Lerner (2001), Solé and Coll (2004), Sampaio (2004), Sacristán (2000, 2007), among others, theoretically substantiate this work. For the research, we have the participation of eight children, in two different schools, regularly enrolled in the early grades of elementary school without cognitive impairment with report and contained in their school records at least two years of failure. The data collection procedures was based on field research conducted by two semi-structured individual interviews with each individual participant (SZYMANSKI, 2002; GASKELL, 2010). Interview data were interpreted, discussed and presented from the themes generated in three stages of analysis (LEFREVE, A. M. e LEFREVE, F. 2005; FLICK, 2009). This study showed that certain methodological practices produced on children characteristic meaning of a teaching focused on reproductivist perspective that children under the research prioritizes the volume of contents, copying and does not value the error as an inherent part of learning.
\end{abstract}

Keywords: School failure. Multifailured children. Teaching methodologies. Elementary School.

\section{RESUMEN}

Este estudio tuvo como objetivo investigar sobre las expectativas de los niños con respecto a la historia de la desaprobación lecciones experimentadas por ellos en los primeros grados de la escuela primaria. La investigación tuvo como objetivo identificar los significados del contexto escolar a través de las voces de los niños multirepetentes (en

\footnotetext{
*Financiamento CAPES.

**Doutoranda do Programa de Pós-Graduação em Educação na UNIVALI. Profesora de Avaliação Educaional no Curso de Pedagogia da APEX. E-mail: <gabimfischer@gmail.com>.

*** Pós.Doutorado em Políticas Púbicas de Currículo e Avaliação realizado na Barry University, USA. Doutora em Educação: Curriculum and Instruction realizado na Florida International University, USA. Líder do Grupo de Pesquisa: Políticas e Práticas de Currículo. Vice-Coordenadora e Professora do PPGE UNIVALI.E-mail: < gesserv@univali.br>.
} 
los?) años de Educación Primaria iniciales (2 a 4 años). Autores como Patto (2008), Charlot (2009 y 2000), Vygotsky (1984, 2007); Herrero (1996), Lerner (2001), Solé y Coll (2004), Sampaio (2004), Sacristán (2000, 2007), entre otros, en teoría, corroboran este trabajo. Para la investigación, contamos con la participación de ocho hijos, en dos escuelas diferentes, matriculados regularmente en los primeros grados de la escuela primaria sin deterioro cognitivo con el informe, que figura en sus registros de la escuela por lo menos dos años de fracaso. Los procedimientos de recolección de datos se basan en una investigación de campo realizada por dos entrevistas individuales semi-estructuradas con cada participante (SZYMANSKI, 2002; GASKELL, 2010). Datos de las entrevistas fueron interpretados, discutidos y presentados a partir de los temas generados en tres etapas de análisis (LEFREVE, A. M. e LEFREVE, F., 2005; FLICK, 2009). Este estudio mostró que ciertas prácticas metodológicas producidas en los niños el significado característico de una enseñanza centrados en perspectiva reproductivista que los menores de la investigación prioriza el volumen de contenidos, copiar y no valoran el error como parte inherente del aprendizaje.

Palabras clave: El fracaso escolar. Niños multirepetentes. Metodologías de enseñanza. La Escuela Primaria.

\section{INTRODUÇÃO}

Historicamente, a reprovação é um problema no âmbito da Educação que nos persegue, preocupa e denota o fracasso do ensino e da aprendizagem na escola. A temática permeia discursos políticos, sociais e educacionais, ao longo da história brasileira, no anseio de compreender e executar ações mais pontuais para a qualidade da educação de todas as crianças matriculadas nas instituições de ensino (CHARLOT, 2000).

Por esse viés, o que carece ser pesquisado e aprofundado? A partir da década de 1970, reflexões provenientes da questão social versus questão pedagógica trouxeram uma nova roupagem para discussão da não aprendizagem dos alunos.

[...] embora não negue a dimensão social do problema, a questão do fracasso escolar, é, também, uma questão pedagógica que requer a investigação de situações e práticas de ensino e que exige que sejam levadas em consideração a própria atividade, a natureza dos sabres transmitidos pela escola, a singularidade dos alunos, a temporalidade da história deles, a conflitualidade social; é uma questão que requer, ainda, uma análise do próprio fracasso, que não é simplesmente o avesso do êxito, definido pela falta, ausência, carência (CHARLOT, 2009, p. 21).

O fracasso escolar como questão didática pedagógica começou timidamente a crescer, procurando definir melhores condições de acesso à aprendizagem da criança repetente, com dificuldades de assimilação de conhecimentos. Patto (2008) discorre sobre esse momento crucial no avanço dos estudos diante do fracasso escolar, contando como a natureza intraescolar passou a ser percebida nesse contexto:

[...] a partir de duas afirmações inicialmente não conciliadas - 'as causas estão na escola' $x$ 'as causas estão na clientela' - produziu-se uma terceira que as integrava: a escola é inadequada para as crianças carentes, uma escola supostamente adequada às crianças das classes 'favorecidas' estaria falhando ao tentar ensinar, com os mesmos métodos e os mesmos conteúdos, crianças culturalmente 'deficientes' ou 'diferentes' (PATTO, 2008, p. 128).

Observa-se, ao longo da história, que a escola foi constituída para as classes dominantes. Nessa perspectiva, percebe-se que as crianças de famílias mais favorecidas chegam à escola com um capital cultural e linguístico, adquirido em seu meio social, próximo das práticas escolares instituídas. Já as crianças de camadas populares, que adquiriram em seu contexto social outra linguagem, são reprovadas na escola. Seus padrões não condizem com o nível cultural da escola. Sendo assim,, ressalta-se que a cultura escolar está mais próxima das classes privilegiadas (RESENDE, 2006).

Sawaya (2002) compartilha o pensamento de Resende (2006) ao evidenciar que as perspectivas atuais para explicar o fracasso escolar são aquelas que buscam compreender os aspectos intraescolares do processo, afirmando que este não acontece por privação cultural, mas sim pelo fato de que o currículo formal não foi pensado para essas crianças, e sim pela classe média dominante.

Diante dessas indagações, o presente estudo levanta algumas questões para discussão: "O que as crianças com histórico de reprovação pensam sobre suas vivências na escola?"; "Que sentidos o processo ensino-aprendizagem tem para elas?"; "Como concebem o cotidiano e as práticas escolares que estão inseridas?”. Esta pesquisa vem contemplar o ponto de vista das crianças, permitindo que os excluídos historicamente sejam ouvidos.

O estudo constitui-se de uma abordagem qualitativa ante a temática da repetência, não pelo viés dos professores, dos pais, ou da sociedade, mas sim pela voz dos sujeitos protagonistas da instituição escolar: as crianças. Campos (2008) afirma que, para saber mais sobre esse "terreno fértil", saber o que as crianças gostam, o que elas pensam, o que desejam, enfim, para dar-lhes 
"vozes", é preciso redimensionar as pesquisas, visto que estudos apontam para a crescente necessidade de uma sociologia da infância.

Por meio de um levantamento bibliográfico no site da Capes, pode-se perceber que muitos são os estudos existentes sobre essa temática, mas poucos trazem a voz das crianças nessas discussões téorico-metodológicas. $\mathrm{Ou}$ seja, quem efetivamente vivencia o "não aprender" ainda é pouco ouvido. Concordo com Patto (2008) quando afirma que na pesquisa educacional brasileira o discurso das crianças é muito pouco valorizado, sendo invariavelmente substituído por um discurso adultocêntrico, retórico e questionável sobre elas.

Escutar o que os "não adultos" pensam sobre a Educação é relevante, já que permite, entre outros aspectos, considerar o seu potencial aprendente, o qual geralmente é excluído. Permite ainda que esse sujeito central da escola de quem pouco se ouve, mas muito se fala, participe dessa discussão com a finalidade de sugerir aos professores a escolha de estratégias mais eficientes, as mediações mais apropriadas para a aprendizagem e a superação da repetência.

\section{Cenário e procedimentos DA PESQUISA}

Ao considerar a natureza da problemática, os procedimentos metodológicos caracterizam essa investigação como uma abordagem qualitativa. Lüdke e André (1986) afirmam que o estudo qualitativo permite a compreensão do fenômeno em seu contexto natural, possibilitando a compreensão de significados por meio de dados descritivos.

A coleta de dados foi realizada nos meses de setembro, outubro e novembro do ano de 2011, em duas escolas municipais de um município catarinense, localizadas uma na zona norte e a outra na zona sul da cidade. A escolha das escolas tomou como base os seguintes motivos: ambas possuírem turmas apenas das séries inicias $\left(1^{\circ}\right.$ ao 5 o ano), o que possibilitou encontrar um maior número de crianças dentro dos critérios da pesquisa; pelo fato de as escolas possuírem em seus dados estatísticos um número expressivo de crianças com defasagem idadesérie; e pelo fato de as instituições estarem localizadas em zoneamentos diferentes do município, uma na zona norte outra na zona sul.

Os sujeitos da pesquisa são crianças matriculadas nos anos iniciais do Ensino Fundamental ( $2^{\mathrm{O}}$ ao $5^{\mathrm{O}}$ ano), que não possuem nenhum comprometimento cognitivo com laudo e que no seu histórico escolar consta mais de um ano de reprovação. Participaram quatro crianças em cada uma das duas escolas, totalizando oito sujeitos. A escolha dessas crianças deu-se por meio de conversas com as orientadoras das escolas. Com o intuito de preservar as identidades escolares, usamos pseudônimos para identificar as escolas. A Escola 1 denominou-se "Castelo Encantado" e a Escola 2, "Reino da Fantasia". As crianças foram nomeadas por nomes comuns aos personagens dos contos de fada. O motivo da escolha deu-se pela relação que se fez com os personagens das literaturas clássicas e com os sujeitos da pesquisa. Refletiu-se da seguinte forma: assim como nas narrativas resolver conflitos culmina em um final feliz; na escola, refletir e planejar novas ações diante da problemática da repetência também pode culminar numa trajetória mais alegre para esss e tantas outras crianças com vivências de reprovação.

Solicitou-se aos responsáveis pelas crianças a autorização do Termo de Consentimento Livre e Esclarecido (TCLE). Juntamente com a autorização dos pais, optou-se por esclarecer também a criança em relação ao objetivo do trabalho e ao convite em participar, tendo o cuidado de respeitar a opinião da criança por considerá-la um sujeito que possui direitos (CRUZ, 2008). As crianças consentiram verbalmente e sob a assinatura do seu nome, no $\mathrm{TCLE}=$ a participação voluntária, disponibilizando com seus familiares uma parte do seu tempo para os encontros necessários para a pesquisa (que eram opostos ao período que estudavam).

A coleta de dados foi realizada por meio de duas entrevistas semiestruturadas e individuais com cada sujeito da pesquisa, em dois encontros alternados. Isso para que o diálogo com a criança não se tornasse cansativo e não ocorresse num único dia. O tempo médio para cada entrevista foi de aproximadamente 15 a 30 minutos, oscilando a quantidade conforme o envolvimento de cada criança durante a conversa. Para análise, as respostas foram agrupadas por meio de eixos de significância. Utilizaram-se nomes fictícios para preservar a identidade da criança, e entre parênteses constam sua idade e os anos de repetência.

\section{CURRÍCUlo E METOdologia de ENSINO: A VOZ DE CRIANÇAS MULTIRREPETENTES}

Cada modalidade educativa tem um currículo com funções específicas por meio do qual o conhecimento é distribuído na sociedade. Na escola, cabe ao professor esse papel de "distribuidor", dando vivacidade aos conhecimentos historicamente produzidos, por meio de propostas metodológicas potentes para a faixa etária que leciona. Nesse movimento, o docente entrelaça em suas aulas currículo e metodologia, no intuito de contemplar boas aprendizagens para os educandos. De acordo com Sacristán (2000), o currículo e a metodologia se relacionam de tal maneira que instrumentalizam a ação pedagógica na escola realizada pelo professor, suscitando boas ou não tão boas aprendizagens. 
Sampaio (2004) ressalta que a aprendizagem precisa acontecer num processo vivo e relacional de conhecer e aprender. Nesse processo, o professor tem um papel fundamental diante do currículo, já que as condições em que o docente realiza o ensino e controla os resultados, ou seja, "como faz", podem tornar a aprendizagem dos alunos mais ou menos qualitativa. Dentre várias questões relatadas pelas crianças, discutem-se as que mais se assemelharam entre as que participaram da pesquisa, que foram: o volume de conteúdos, a prática da cópia na escola, a quantidade de tempo que permanecem dentro da sala, a possível ausência da finalidade social nas atividades realizadas e a aversão ao erro no cotidiano da sala de aula.

Um dos itens citados na dinâmica das aulas foi a grande quantidade de conteúdos realizados por meio de disciplinas e atividades propostas pelos professores. As crianças expressaram suas opiniões relatando o desconforto quanto ao volume de conteúdos que lhes são propostos. Vejamos alguns depoimentos:

Pesquisadora: Me conta como são as aulas assim, elas são, interessantes? São cansativas? São chatas? São diferentes? São divertidas? Como é que são as aulas? Bela Adormecida: Ah, eu, tipo assim, eu não gosto, assim, sabe? Porque, tipo assim, a professora não passa, a professora passa bastante coisa, meu, ela passa conta, e ela passa aquelas conta que tem que escrevê os número, e eu não so muito pegada, sabe?

- (...) terminô, nós vamos pro outro caderno. Já sabe não é o mesmo caderno que a gente só fica, num caderno só, ela só pega e vai pra outro e é tudo a mesma coisa, assim vai enchendo na cabeça, dai começa a cansá, daí eu não penso muito, sabe? (Bela Adormecida - 11,2)

João do Pé de Feijão considera difícil a disciplina de Geografia, pelo fato de realizar muitas atividades no livro didático e tirar notas baixas no boletim:

Pesquisadora: Então, quais atividades que você acha mais dificeis de fazer?

João do Pé de Feijão: Hmm... Geografias... é... geografias.

Pesquisadora: Por quê? Como é que é?

João do Pé de Feijão: Porque eu não se dou bem... no meu boletim eu tirei dois em geografias.

Pesquisadora: Hmm... mas o que vocês fazem em Geografia?

João do Pé de Feijão: ...ssora só passa... passa... passa... é de coisa de livro e um monte de problema pra nóis resolver. (João do pé de Feijão - 10,2)

O volume desses conteúdos tem relação com outra prática vivenciada por todas as crianças participantes da pesquisa: a cópia. Quando perguntei sobre o que elas não gostavam de fazer, três delas foram enfáticas ao dizer que fazer cópia é algo muito cansativo.

Pesquisadora: E, aqui na escola, uma coisa que você não gosta de fazer?

Chapeuzinho Vermelho: Que eu não gosto de fazer é cópia, tenho preguiça.

Pesquisadora: Fazer cópia? Por quê?

Chapeuzinho Vermelho: Porque assim a cópia que a professora passa é muito grande e se eu não copiar eu fico na sala, dai eu vou e copio rapidinho pra poder sair. Daí então cópia que eu não gosto. (Chapeuzinho Vermelho-10,2)

Pesquisadora: E o que você acha, aqui na escola, menos interessante, cansativo, chato, que você não gosta de fazer?

Robin Wood: Pegar aquele texto do livro e escrever tudo, uma folha inteira. (Robin Wood-11,2)

A atividade da cópia é vivenciada diariamente em diferentes disciplinas. Apesar de ser o exercício de copiar do quadro uma das únicas coisas que Gato de Botas consegue fazer na disciplina de Língua Portuguesa, ele também diz não gostar devido ao excesso praticado:

Pesquisadora: E em Português, o que você já consegue fazer?

Gato de Botas: Português, sei copiar do quadro, só. Pesquisadora: Vocês fazem bastante cópia?

Gato de Botas: Aham. Dai a gente fica atrasado. Por causo que a professora passa um atrás da outra. (Gato de Botas - 10,3)

A cópia na escola é utilizada também como castigo. Chapeuzinho Vermelho narra uma situação de indisciplina na aula de Educação Física. Ocasião em que a turma foi castigada, ficando na sala de aula e copiando do quadro "o que não devem fazer nas aulas":

Chapeuzinho Vermelho: Só que daí eu comecei a cantar, os meus amigos foram atrás de mim... só que dai como o Tiago faz coisa, a gente não ficou na aula de Educação Física brincando. Fomo copiar cópia, por causa de alguns, e eu também tava nesse clima de bagunça na escola. Aí como eu fiz, os meus amigos todos ficaram sem aula de Educação Física por culpa minha. Aí eu não concordei com a professora de Educação Física, porque a gente não devia... (Chapeuzinho Vermelho - 10,2)

O problema apresentado aqui não está na atividade em si da cópia, mas na maneira como é utilizada com as crianças. Cagliari (1998) se opõe a determinadas ações que envolvem a cópia, dizendo que os professores têm 
consciência de que essa atividade em grande escala é exaustiva e consiste numa repetição mecanizada de determinado conteúdo. Por essa razão, utiliza-se dela erroneamente, até para casos de punição quanto à indisciplina. Considera-se importante destacar nesse contexto a fala de Bela Adormecida:

Pesquisadora: Ela ensina no quadro?

Bela Adormecida: Ela ensina no quadro. Nóis, pra gente aprende bastante, sabe, e ela só ensina uma vez...

Pesquisadora: Ah, ela só ensina uma vez?

Bela Adormecida: Só uma vez. (Bela Adormecida $-11,2)$

Isso faz com que se pense que os professores, tendo consciência ou não das concepções que estão por detrás de suas práticas, dispõem de referenciais que norteiam suas atuações com instrumentos praticados no desenvolvimento do trabalho com as crianças (WEISZ, 2006). Desse modo, realizar reflexões que visam a perceber $o$ que se $f a z$ e o porquê se faz, a fim de compreender quais referenciais teóricos estão guiando, fundamentando e justificando suas ações, torna-se algo de grande importância aos docentes (SOLÉ e COLL, 2004).

Outras características quanto ao ensino e aprendizagem podem ser percebidas em outro momento da fala de Bela, quando a menina demonstra em seu discurso o controle da aprendizagem nas mãos do professor:

- [...] eu vou dar uma prova pra vocês, dai vocês vão treinar, vão lê como é que é, dai a professora vai passar, vocês vão prestar atenção na profe. A profe vai explicar certinho e vocês vai colocar no papel. (Bela Adormecida - 11,2)

Bela, em seu relato, traz características pontuais de como o docente ensina seus alunos, explicando que é o professor quem ensina, é ele quem determina os conteúdos, e que cabe às crianças prestar atenção, reproduzir, treinar e registrar "certinho" os resultados. Porém, estudos pautados na concepção construtivista, que norteiam os grandes documentos da Educação Nacional do país, dos estados e municípios, desmistificam essa maneira de aprendizagem da criança, enfocando outra abordagem no processo de aprendizagem, como aborda Solé e Coll (2004):

A aprendizagem contribui para o desenvolvimento na medida em que aprender não é copiar ou reproduzir a realidade. Para a concepção construtivista aprendemos quando somos capazes de elaborar uma representação pessoal do objeto da realidade ou conteúdo que pretendemos aprender.
Essa elaboração implica aproximar-se de tal objeto ou conteúdo com a finalidade de apreendê-lo; não se trata de uma aproximação vazia, a partir do nada, mas a partir das experiências, interesses e conhecimentos prévios que, presumivelmente, possam dar conta da novidade (SOLÉ e COLL, 2004, p. 19).

Quando isso ocorre, pode-se dizer na concepção construtivista que a criança está aprendendo significativamente, ou seja, está atribuindo sentido. De acordo com a percepção das crianças entrevistadas, as aulas são pouco interessantes. Eis aqui mais uma questão que emergiu nos discursos dos sujeitos entrevistados em relação à metodologia, o fato de permanecerem muito dentro da sala de aula:
Como são as aulas?
João do Pé de Feijão: Algumas são legais, outras são chatas.
Pesquisadora: Como que é uma aula chata?
João do Pé de Feijão: É só ficar dentro da sala, não ficar fazendo nada... (João do pé de feijão - 10,2).

Com a mesma opinião, seguem os depoimentos de Gato de Botas e Robin Wood:

\section{Pesquisadora: E o que você menos gosta? \\ Gato de Botas: O que eu menos gosto? Ficar dentro da sala e a aula de Inglês. (Gato de Botas - 10,3) \\ Robin Wood: E eu não gosto de ficar muito tempo na sala... Muito tempo na sala me deixa nervoso. (Robin Wood - 11,2)}

João do Pé de Feijão e Cinderela reclamam do ambiente fechado, mas em seus depoimentos dão "dicas" do que consideram uma aula mais significativa, que procura unir o "passear" com o "estudar":

Pesquisadora: $E$ as aulas geralmente você acha que são interessantes, cansativas, chatas, diferentes, legais?

João do Pé de Feijão: Diferentes, porque cada dia nós faz uma aula diferente da outra. Mas é ruim quando nós fica enfornado dentro da sala, só fica lá dentro, e é melhor quando nós vamos sair, fazer passeios no ar livre, pra estudar, pra fazer atividades, pra fazer trabalhos sobre esse lugar. (João do Pé de Feijão $-10,2)$

Pesquisadora: Todo dia é um dia diferente? Ou os dias são mais ou menos parecidos?

Cinderela: Mais ou menos parecidos, né? Tudo a mesma coisa. (Cinderela-10,2)

A menina deixa claro em sua fala que as aulas são mais ou menos parecidas, quase sempre acontecem as 
mesmas coisas, não demonstrando durante as entrevistas nenhum entusiasmo em relatar algo que está aprendendo ou realizando de novo em sua turma. Para que a aprendizagem tenha significado, o interesse em aprender precisa ser sentido, mobilizado na criança, preenchendo uma necessidade própria (SOLÉ e COLL, 2004). Quando se perguntou sobre as produções de texto que as crianças faziam na escola, emergiu uma possível ausência da função social nas práticas metodológicas como outro ponto importante a ser discutido. Segundo Cinderela e João do Pé de Feijão, escrever texto é algo puramente escolar, feito para a professora, porque ela solicita, e para gerar uma nota:

Pesquisadora: E vocês escrevem o texto para colocar no mural? Pra fazer outras coisas, ou vocês escrevem textos pra professora dar uma nota?

Cinderela: Porque a prôfaz assim, oh: ela pega pra dá nota no diário dela e pra passar no boletim. (Cinderela $-10,2)$

Pesquisadora: E vocês fazem o texto pra ter uma nota? João do Pé de Feijão: Aham.

Pesquisadora: O texto é pra isso?

João do Pé de Feijão: É.

Pesquisadora: Aham

João do Pé de Feijão: Nós faz esse texto pra ganhar nota no boletim, pra conseguir nota mais alta e pra conseguir passar...

Pesquisadora: Aham. O texto que vocês fazem serve pra professora dar uma nota, é isso?

João do Pé de Feijão: Aham. É.

Pesquisadora: Vocês não escrevem textos pra outras coisas?

João do Pé de Feijão: Não.

Pesquisadora: Vocês escrevem texto pra receber uma nota?

João do Pé de Feijão: Só... (João do Pé de Feijão $-10,2)$

Diferentemente das crianças acima, na fala de Bela já se pode perceber que há uma proposta de socializar as produções de texto da turma, porém essa finalidade não parece estar muito clara para ela:

Pesquisadora: E o que vocês escreveram? Esse texto foi para algum lugar, ficou no caderno, vocês colocaram num mural?

Bela Adormecida: Tipo assim, a professora, a gente, fizemos o texto, daí pra colocá na frente, assim, sabe? Dai a professora lê, corrigi, pra vê se tem algum erro, e ela colocava na frente assim da escola pra todo mundo vê, dai ela colocou dai depois, assim, ela tirô entendeu? Pesquisadora: Aham.

Bela Adormecida: Depois, ela foi entregando um por um depois que ela corrigiu. (Bela Adormecida - 11,2)
A leitura e a escrita, tradicionalmente, transformaram-se de objeto social a objeto escolar, ocultando funções extraescolares da língua por meio das quais a criança, no processo de aprendizagem, acaba interagindo mecanicamente e contemplativamente diante do objeto (FERREIRO, 1996). Lerner (2001) complementa essa discussão, trazendo a reflexão da necessidade de a escola ser uma microcomunidade de leitores e escritores, oportunizando às crianças uma versão escolar das práticas de linguagem pautadas numa fidelidade à versão social. Como necessidade institucional ao ensino das práticas de linguagem, a autora explica sobre a conciliação dos "propósitos didáticos" aos "propósitos sociais", por meio de uma organização curricular pautada em modalidades organizativas que permitam aos professores e crianças orientarem suas ações com finalidades sociais claras. De acordo com Lerner:

O desafio é conseguir que a escrita deixe de ser na escola somente um objeto de avaliação, para se constituir realmente num objeto de ensino; é prática, sabendo - por experiência, não por transmissão verbal - que é um longo e complexo construído por operações recorrentes de planejamento, textualização e revisão (LERNER, 2001, p. 28).

Além disso, combater a discriminação que a escola produz não apenas com aqueles que não consegue alfabetizar, mas, também, com os demais que não fracassam explicitamente por meio da reprovação. Já que estes passam anos na escola e não se tornam produtores e leitores de textos competentes. Outra problemática que necessita ser pensada.

Bela, no final da sua fala, traz à tona o quarto aspecto de grande relevância em torno da metodologia vivenciada pelas crianças, a questão do erro. Para praticamente todas as crianças da pesquisa, errar é algo muito ruim. Segundo Bela Adormecida, a própria professora cobra que a leitura, mesmo na fase inicial, já seja realizada corretamente, sem gaguejar:

Bela Adormecida: (...) tu não pode confundir a palavra, tu não pode inventar uma palavra pra falar pra professora, tem que falar direto. Não gaguejando, tu tem que ler tipo inteiro uma palavra, porque se tu não vai com muita atenção, a professora vai te dar ajuda, vai dar reforço, essas coisas. (Bela Adormecida $-11,2)$

Perguntou-se ao João do Pé de Feijão em que momento sua professora costuma elogiar os alunos. Ele explicou que é quando eles acertam:

João do Pé de Feijão: Quando a pessoa é um bom aluno e faz tudo, as coisas, não erra, sim, não deixa incompleto. (João do Pé de Feijão - 10,2) 
De acordo com João, o elogio da professora está muito ligado ao acerto, ao certo, ao padrão. É lógico que acertar é muito melhor do que errar, porém quem erra também pensa, e refletir sobre o caminho equivocado que a criança $a$ priori escolheu é uma ótima oportunidade para novos conhecimentos serem mediados e construídos por uma turma. Errar na frente dos amigos é também algo vergonhoso, feio e passível de ser ridicularizado pela turma, como contou Gato de Botas no momento em que recebeu a prova com os erros e nota baixa:

Pesquisadora: Entendi. E quando ela entrega essas folhas de exercícios com a nota, ela fala alto a nota do amigo?

Gato de Botas: Não, só vai olhando... mais todo mundo vai lá, abre o caderno da gente e vê, e ficam caçoando. (Gato de Botas - 10,3)

João contou que sua professora costuma falar a nota da prova em voz alta para a turma toda ouvir, e isso conota mais uma vez como errar é motivo de deboche:

Pesquisadora: E os amigos riem mesmo? O que eles fazem?

João do Pé de Feijão: Aham... Ficam falando que é burro, que não estuda, que não sabe nada... (João do Pé de Feijão - 10,2)

Diante dessa crucificação pelo erro, as crianças constroem significados ruins e passam a não querer errar de jeito nenhum. Sendo assim, acabam, por vezes, utilizando a alternativa de copiar a resposta certa do quadro ou do amigo, mesmo que a professora não aprove, como uma saída para acertar e fugir dos comentários maldosos, conforme disse Robin Wood:

Pesquisadora: E o que vocês não podem fazer na sala de jeito nenhum, que a professora não deixa?

Robin Wood: É passa o resultado pro outro.

Pesquisadora: Dar o resultado pro outro?

Robin Wood: É. Que nem tem um piá, né, ele é, fica chutando os números, depois que ele vê que tá certo, ele vai lá e dai a professora dá certo! (Robin Wood $-11,2)$

Perguntado sobre as características de um "mau aluno" e de uma "criança inteligente", o aspecto do erro também voltou a ser explanado por Branca de Neve:

\section{Pesquisadora: E um mau aluno?}

Branca de Neve: Faz bagunça e leva errado. Erra as atividades.

Pesquisadora: E como é uma criança inteligente?

Branca de Neve: Ela é a... uma criança inteligente ela sabe tudo e não erra nada. (Branca de Neve - 10,2)
Mas desde quando o erro passou a ser bem visto na escola? Ao longo do século XX, com o surgimento de novas teorias de aprendizagem, por meio de estudos de Piaget, Vigotsky e Ausubel, a questão do erro na aprendizagem passou a ser tratada de maneira diferente. Essas teorias repensaram "o erro", afirmando que quem erra também pensa e que errado é quem pensa que o erro não tem validade para aprendizagem. Segundo esses pesquisadores, os erros são obstáculos que fazem parte da aprendizagem. Indicam o raciocínio da criança, permitindo que o professor crie situações de aprendizagem nas quais o sujeito apresente suas ideias iniciais equivocadas em xeque, ampliando e ressignificando seus conhecimentos por meio de reflexões diante do que errou.

Analisando os erros das crianças, categorizando e problematizando por meio de situações de aprendizagem reflexivas e bem focadas, o erro se torna parte da aprendizagem, pois possibilita à criança fazer o que Piaget chamou de autorregulação. Para que haja uma aprendizagem efetiva, não é suficiente desenvolver a atividade e mostrar a incoerência, "o erro" para a criança; mas sim intervir por meio de questionamentos, para que a criança perceba o seu raciocínio inicial e repense sobre "por que errou e onde errou", autorregulando sua aprendizagem.

Por outro lado, também nas falas das crianças, emergiram pontos positivos relacionados ao currículo e à metodologia. Branca de Neve diz gostar mais de Educação Física, justificando sua escolha por causa da postura do professor:

\section{Branca de Neve: Educação Física. \\ Pesquisadora: Ah é? Por quê? \\ Branca de Neve: Porque... o professor explica as coisas. (Branca de Neve-10,2)}

Já para Gato de Botas e João do Pé de eijão, fazer aula de Educação Física é bom pelo fato de que nesse momento eles se sentem livres e fazem coisas que criança gosta:

- Gato de Botas: Eu gosto de estudar.. o que eu mais gosto é de Educação Física livre, porque dá pra fazer tudo. Que eu mais faço na Educação Física é tocar pandeiro de vez em quando. (Gato de Botas - 10,3)

João do Pé de Feijão: A Educação Física.

Pesquisadora: Por quê?

João do Pé de Feijão: Porque ela... ela, assim, porque não fica dentro da sala, fica brincando, correndo, fazendo atividades pra se aquecer. Enós fica brincando assim no ar livre, não fica dentro da sala enfornado assim. (João do Pé de Feijão - 10,2)

Para Rapunzel, fazer aula de Educação Física é a mesma coisa que "brincar", e isso muito lhe agrada: 
Pesquisadora: Educação Física?

Rapunzel: Aham.

Pesquisadora: Por quê?

Rapunzel: É porque é legal, eu gosto de brinca. (Rapunzel - 10,2)

Cantar, tocar um instrumento, correr, brincar, são necessidades das crianças, visto que são ações típicas da cultura infantil, que lhes trazem alegria e satisfação. Para Motta (2011):

As crianças são vistas como produtoras de cultura e exprimem através de suas percepções e interações com os pares ou os adultos. As culturas infantis apresentam especificidades, como os modos como o lúdico e o faz de conta são incorporados (MOTTA, 2011, p. 164).

As especificidades da cultura infantil são oralizadas pelas crianças multirrepetentes, pois brincar, jogar, produzir algo, construir, criar, explorar materiais diversificados são atividades que elas gostam de realizar. Cinderela e Chapeuzinho Vermelho exemplificam o que fazem na aula de Arte, justificando sua preferência por essa disciplina:

Chapeuzinho Vermelho: A gente faz recorte, a gente aprende as cores, a gente até fez um negócio lá de cores... (Chapeuzinho Vermelho - 10,2)

Pesquisadora: O que tem aqui na sua escola que você gosta bastante?

Cinderela: Ah, o pólo de artes...

Pesquisadora: O pólo de artes, que é tipo uma escolinha de artes que vocês têm, né? Me explica como é isso, eu não sei muito bem...

Cinderela: É... Hmm..., a prô fala que é pra gente desenhá, né? Ela tem um quadro de desenho, um quadro branco, dai a gente faz de uma tela aquelas pequena lá, oh, sabe? (Cinderela - 10,2)

Nessas e nas demais disciplinas, as crianças relataram alguns momentos relacionados à metodologia empregada pelos docentes. Em seus depoimentos, pôde-se perceber quais ações metodológicas as crianças consideraram mais significativas no contexto escolar e que as ajudaram a aprender. João do Pé de Feijão e Cinderela estudaram no ano anterior, na mesma sala. Ambos contaram que aprenderam conceitos matemáticos por meio de um projeto chamado "Coleção de tampas". Nesse trabalho, as crianças classificavam por cores as tampinhas coletadas e realizavam cálculos:

João do Pé de Feijão: Quando eu aprendi com a professora Aline, e ela pediu pra nóis fazer a tarefa de casa, trazê um monte de... aquele lá..., aquelas tampinhas de garrafa. Daí eu aprendi ali... (João do Pé de Feijão - 10,2)

Cinderela: Fica mais fácil né, dai a gente conta, tira, daí conta até nove, dai tira mais um daí. (Cinderela $-10,2)$

Para os sujeitos pesquisados, as aulas que frequentaram, ou frequentam, de "reforço escolar" ou de "apoio" também possibilitaram experiências significativas de aprendizagem. Rapunzel relata a metodologia da professora, explicando como ela ensina:

- Ah, ela ensina as pessoas, pega um livrinho, dai ensina a lê, dai depois ela manda lá pro computador, lá, dai ela bota coisa de continha.

Pesquisadora: Dai você acha melhor assim, desse jeito?

Rapunzel: Aham. (Rapunzel - 10,2)

Chapeuzinho Vermelho conta com entusiasmo que aprendeu Matemática no reforço e exemplifica outras vivências dessas aulas:

Chapeuzinho Vermelho: Eu até vinha pro reforço de Matemática, dai foi aonde eu aprendi com elas Matemática... Lá tem também computador. Só que lá tem aquelas pecinhas vermelhas, dai a gente encaixa lá, dai ela coloca jogo de... de tabuada, de continhas, e dai en coloquei o jogo do Aladim e daí eu acertei. Lá tem os jogos da conta. (Chapeuzinho Vermelho-10,2)

Sacristán (2000) explica que o valor do currículo se comprova na maneira pela qual se concretiza em situações reais. Os depoimentos acima denotam esse valor. As tarefas escolares propostas pelos professores podem potencializar o aprendizado das crianças na medida em que estejam vinculadas a situações de aprendizagem significativas e com intencionalidades claras para o professor.
Se o currículo é a ponte entre teoria e ação, entre intenções ou projetos e realidade, é preciso analisar a estrutura da prática onde fica moldado. Uma prática que responde não apenas às exigências curriculares, mas está, sem dúvida, profundamente enraizada em coordenadas prévias a qualquer currículo e intenção do professor (SACRISTÁN, 2000, p. 201).

Segundo o autor, analisar a prática pedagógica na qual se projetam determinações do sistema curricular é fundamental para que ações diante do currículo possam ter efeitos educativos por meio de experiências do contexto escolar que contemplem as reais necessidades das crianças. Todas as crianças da pesquisa que já frequentaram, ou frequentam, essas aulas de reforço, que 
acontecem no contraturno do seu horário de aula, dizem que esse momento paralelo de aprendizagem ajudou-as a aprender:

Rapunzel: O reforço ajuda. (Rapunzel - 10,2)

Pesquisadora: E você acha que o reforço está ajudando?

Rapunzel: Tá!

Pesquisadora: O que você aprende no reforço?

Rapunzel: Aprendo a fazê conta, assim, dai a professora bota assim no computador e tem que achar quantos que dá, tem que achá as pecinhas quadradas... (Rapunzel - 10,2)

Bela Adormecida: Daí eu ia pro reforço, tudo, dai eu não sabia escrever nada, nada, nenhuma palavra. Dai eu fui aos pouquinhos, ainda não sei muito, né? (Bela Adormecida - 11,2)

João Pé de Feijão: Ajudou. Porque ajudou mais na leitura, porque a ....ssora mandava nós ficar lendo... ensinava atividade pra ler. (João do Pé de Feijão - 10,2)

Pesquisadora: Valeu a pena? Você acha que o reforço te ajudou?

Branca de Neve: Me ajudou. (Branca de Neve - 10,2)

No momento da coleta de dados, cinco das oito crianças não estavam mais frequentando as aulas de reforço. Algumas saíram por causa do horário (os pais não podiam levá-las ou consideraram o horário muito cedo); outras, por motivo de muitas faltas (mais de três faltas justificadas ocasionavam a perda da vaga nas aulas do reforço); e ainda por já terem aprendido a ler e escrever e receberem "alta" da professora (as crianças recebem "alta" quando conseguem ler um pouco, e sua escrita produz palavras e frases curtas - focam a aquisição mínima do código). Diante dessa proposta das instituições participantes em oportunizar as crianças com dificuldade de aprendizagem um outro momento no contexto escolar para sanar suas defasagens. (frase incompleta) Nos discursos das crianças, essa experiência de aprendizagem, chamada reforço escolar, é importante para suas aprendizagens. Estudos de Vygotsky (1984) postulam que o indivíduo, por ser interativo, constitui-se na relação e na mediação com os outros.

Perguntou-se também às crianças a respeito da escola, como era, o que achavam se gostavam ou não de estarem ali. Muitas delas responderam positivamente, exemplificando o que mais gostavam ou consideravam interessante. João do Pé de Feijão exemplificou no seu "gostar" a interação com as demais crianças:

Pesquisadora: E você gosta da escola?

João do Pé de Feijão: Eu gosto, porque ela é bem legal, ela tem bastante pessoas pra fazer amizade e todo dia, quando vem gente nova, nós faz amizade com as pessoa. (João do Pé de Feijão - 10,2).
Fazer novas amizades, interagir, trocar experiências, são ações que João considera interessante. $\mathrm{O}$ ambiente escolar, espaço em que as crianças passam boa parte do seu tempo, é um dos lugares, em tese, propícios para a infância, permitindo o exercício de interações sociais. E o trabalho escolar não se limita na sala de aula, mas se configura nesse espaço prazeroso e acolhedor onde as crianças podem se sentir parte, o que favorece a aprendizagem. As meninas Branca de Neve e Rapunzel também disseram gostar da escola, sinalizando a questão do aprender e do brincar nesse contexto:
Pesquisadora: Gosta? Por que você gosta?
Branca de Neve: Porque é legal de brincá, fazer tudo... (Branca de Neve-10,2)
Pesquisadora: Você gosta de vir para a escola? Gosta? Rapunzel: Gosto.
Pesquisadora: Por quê?
Rapunzel: Porque é legal.
Pesquisadora: Mas o que tem aqui que é legal?
Rapunzel: É que o professor ensina a gente assim, aprendê a fazê ginástica, aprende a gente brincá, dai a ...ssora ensina a gente escrevê assim, ensina a gente a fazê continha...
Pesquisadora: Entendi, e você gosta de estudar?
Rapunzel: Gosto. (Rapunzel-10,2)

Aprender e brincar são ações que as meninas consideram parte do contexto escolar e que para elas é significativo. O papel da professora nesse aprender é exemplificado por Rapunzel, colocando o docente com agente central desse processo. Ensino e aprendizagem são processos distintos. O primeiro diz respeito ao professor, e o segundo, ao aluno (Weisz, 2006). Os dois se comunicam, dialogam constantemente, e cabe ao professor perceber como a aprendizagem do aluno acontece para ministrar situações de ensino que o ajude a avançar de um patamar que já conquistou para outro mais elevado.

$\mathrm{Na}$ mesma perspectiva das meninas acima, Chapeuzinho Vermelho, Robin Wood e João do Pé de Feijão também ressaltaram o brincar como sendo uma atividade muito gostosa vivenciada na escola:

Pesquisadora: E o que você faz aqui na escola que você acha mais interessante?

Chapeuzinho Vermelho: Interessante, é legal... eu brinco de cavá embaixo da areia, o meu pé fica cheinho de areia...

Pesquisadora: Em que momento você brinca na areia? Chapeuzinho Vermelho: Na hora do lanche.

Pesquisadora: Fora a hora do lanche, não tem outro momento que vocês brincam na areia?

Chapeuzinho Vermelho: Não. (Chapeuzinho Vermelho $-10,2)$ 
Robin Wood: Eu adoro brincar aqui. No recreio, a gente brinca de pega-pega, só que a gente não corre aqui, a gente corre na quadra. (Robin Wood - 11,2)

Pesquisadora: Aham... Que mais que você gosta de fazer?

João do Pé de Feijão: (2b) Ficar brincando com meus amigos... Às vezes, a gente fica ali na quadra estudando, nós pega livro da professora que empresta pra nós, pra ficar lendo. Às vezes, nós vamo brincar no parquinho. Assim que eu gosto. Às vezes, a gente vai jogar bola na areia, Às vezes, nós brinca na quadra de chute a gol; às vezes, a gente brinca de driblinho ali também.

Pesquisadora: E no parquinho vocês vão sempre?

João do Pé de Feijão: Vamos. Todo dia nós vamos lá brincar de pega-pega.

Pesquisadora: Todo dia vocês vão no parquinho, mas isso na hora do recreio?

João do Pé de Feijão: Nós só vamos no parque com a Mirian, só quando a professora falta. Aí ela leva nós, todo dia no final da aula. (João do Pé de Feijão - 10,2)

O brincar apareceu sempre fora de sala de aula, nas falas das crianças, e diante disso questionou-se: sala de aula é lugar de aprender, e recreio é lugar de brincar? Pelos depoimentos das crianças pesquisadas, pôde-se constatar que pensam mais ou menos assim.

\section{CONSIDERAÇõES FINAIS}

Ao analisar os depoimentos dessas crianças multirrepetentes, constatou-se que a ótica infantil carece da necessidade de ser levada em consideração para que a instrumentalização do currículo e da metodologia empregada possa ser cuidadosamente pensada, analisada e julgada. E com seus devidos papéis, não apenas no ensino das crianças de modo geral dos primeiros anos do Ensino Fundamental, mas, especificamente, para as crianças que, em seu histórico escolar, contam reprovações.

As crianças multirrepetentes participantes da pesquisa trouxeram para a discussão aspectos relacionados ao grande volume de conteúdos disciplinares; as frequentes atividades de cópia que realizam, a maneira "chata" pela qual as atividades são desenvolvidas em sala de aula; e ainda a maneira desvalorizada com que o erro é tratado no processo de aprendizagem. Traduzindo seus depoimentos, relataram a maneira pela qual o currículo tem se efetivado em sala de aula e disseram não gostar dessas práticas escolares. Por outro lado, falaram sobre o quanto se sentem mais felizes com experiências mais lúdicas e mais ligadas a brincadeiras.

Dado o fato de que a escola é um ambiente multifacetado, essas variações identitárias podem ser estratégicas na produção de conhecimento e no exercício da cidadania por meio das quais inúmeras aprendizagens acontecem. O currículo e a metodologia envolvem muitas questões relacionadas ao contexto escolar no qual as crianças estão imersas diariamente, por cerca de 200 dias letivos. Identificar quais estratégias são mais significativas e prazerosas para as crianças pode ajudar os professores a compreendê-las como sujeitos de direitos dignos de respeito e cheios de interesses e desejos. Assim, seus professores podem aprender a valorizar seus saberes e necessidades.

A dimensão lúdica é algo espontâneo e necessário para toda criança. Uma especificidade que faz parte da sua natureza, a qual viabiliza seu desenvolvimento e aprendizagem. Dessa forma, as ações da criança, inclusive a brincadeira, são construídas num processo social no qual a escola também se inclui. Por meio dessas nuances, a sociologia da infância traz a reflexão de que a criança, independentemente de sair de uma modalidade de ensino denominada Educação Infantil e ingressar na modalidade seguinte intitulada Ensino Fundamental, não deixa de ser criança; ou seja, não deixa de exercer posturas comuns ao seu grupo social.

Depois da família, em geral, a escola é o segundo espaço social onde cotidianamente as crianças estabelecerão relações com outros. Por ser um lugar planejado e pensado para o seu desenvolvimento, esse espaço precisa ser prazeroso às crianças, de modo que ao longo dos anos de sua escolaridade elas possam não só crescer em estatura física ou cognitiva, mas também nas relações afetivas e emocionais. Pelos depoimentos das crianças, pôde-se perceber que os aspectos considerados relevantes no contexto escolar estão intimamente ligados às necessidades da sua infância e à concepção de ensino e aprendizagem na qual o sujeito faz parte. Além do fato de construírem saberes ao interagir com seus pares a partir de contextos para os quais os conhecimentos têm função social.

O conceito de escola que essas crianças multirrepetentes vêm formando e que levam ao longo de suas trajetórias representa algo que é preciso se repensar e se rever como educadores. Já o conceito de professor, bem como as condutas pedagógicas conservadoras, também causa inquietações e questionamentos. Como exemplo, a gestão de sala de aula e a materialização do currículo. Esse processo gera uma construção de normas e condutas contraditórias em relação ao sujeito que os documentos educacionais dizem querer formar.

Por fim, acredita-se que esta pesquisa traz elementos importantes aos profissionais da educação. Na medida em que as crianças com histórico de repetência puderam compartilhar seus pontos de vista sobre a escola e sobre a maneira pela qual esta vem contribuindo para a construção de sua identidade, de suas trajetórias e de um lugar social 
em suas vidas. Que lugar deveria ser este? E qual lugar será este para crianças que lutam com um histórico de multirrepetência?

\section{REFERÊNCIAS}

BARDIN, L. Análise de conteúdo. Lisboa: Ed. 70, 1979.

BAUER, W.; GASKELL, G.; ALLUM, N. Qualidade, quantidade e interesses do conhecimento: evitando confusões. In: BAUER, M. W.; GASKELL, G. (orgs.). Pesquisa qualitativa com texto, imagem e som: um manual prático. Rio de Janeiro: Vozes, 2010.

CAGLIARI, Luiz Carlos. Alfabetizando sem o ba-be-bi-bo-bu. São Paulo: Scipione, 1998.

CAMPOS, M. M. Por que é importante ouvir a criança? A participação das crianças pequenas na pesquisa científica. In: CRUZ, Silvia Helena Vieira (org.). A criança fala: a escuta de crianças em pesquisas. São Paulo: Cortez, 2008.

CHARLOT, Bernard. Da relação com o saber: elementos para uma teoria. Tradução de Bruno Magne. Porto Alegre: Artmed, 2000.

CHARLOT, B. A construção social da noção de fracasso escolar: do objeto sociomidiático ao objeto de pesquisa. In: ARROYO, Miguel; ABRAMOWICZ, Anete. (orgs.). A reconfiguração da escola: entre a negação e a afirmação de direitos. Campinas: Papirus, 2009.

COLL, César; SOLÉ, Isabel. Os professores e a concepção construtivista. In: COLL, César. (Orgs.). O Construtivismo na sala de aula. São Paulo: Ática, 2004.

COLLARES, C. A. L. O cotidiano escolar patologizado: espaço de preconceitos e práticas cristalizadas. São Paulo, 1995, 194 p. Tese (de Livre Docência) - Universidade Estadual de Campinas, 1995.

COLLARES, C. A. L. Ajudando a desmistificar o fracasso escolar. Ideias, p. 24-28, 1989. Disponível em: <http://www. crmariocovas.sp.gov.br/pdf/ideias 06 p024-028 c.pdf>. Acessado em: 22 abr. 2011.

COLLARES, C. A. L.; MOYSÉS, M. A. A. Preconceito no cotidiano escolar: ensino e medicalização. São Paulo: Cortez, 1996.

CRUZ, S. H. V. (Org.). A criança fala: a escuta de crianças em pesquisas. São Paulo: Cortez, 2008.

FERREIRO,Emília. Com todas as letras. São Paulo: Cortez, 1996.

FLICK, U. Desenho de pesquisa qualitativa. Porto Alegre: Artmed, 2009.

GASKELL, G. Entrevistas individuais e grupais. In: BAUER, M. W.; GASKELL, G. (orgs.). Pesquisa qualitativa com texto, imagem e som: um manual prático. Petrópolis: Vozes, 2010.

GATTI, Bernadete A. Políticas, ações educacionais e desempenho escolar. In: ARROYO, Miguel; ABRAMOWICZ, Anete (orgs.). A reconfiguração da escola: entre a negação e a afirmação de direitos. Campinas: Papirus, 2009.

LEFREVE, A. M.; LEFREVE, F. Depoimentos e discursos: uma proposta de análise em pesquisa social. Brasília: Liber Livro, 2005.

LERNER, Délia. Ler e escrever na escola: o real, o possível e o necessário. Tradução de Ernani Rosa. Porto Alegre: Artmed, 2002.

LUDKE, M.; ANDRE, M. E. D. A. Pesquisa em educação: abordagens qualitativas. São Paulo: EPU, 1986.
MOTTA, Flávia Miller Naethe. De crianças a alunos: transformações sociais na passagem da educação infantil para o ensino fundamental. Educação e Pesquisa [online], v. 37, n. 1, p. 157-173, jan./abr. 2011. Disponível em: <http://www.scielo. br/pdf/ep/v37n1/v37n1a10.pdf >. Acessado em: 28 abr. 2012.

MOYSÉS, M. A. A. A institucionalização invisível: crianças que não aprendem na escola. Campinas: Mercado das Letras; São Paulo: Fapesp, 2001.

MOYSÉS, M. A. A. Fracasso escolar: uma questão médica? Ideias, p. 1-29, 1989. Disponível em: <http://www.crmariocovas. sp.gov.br/pdf/ideias_06_p029-031_c.pdf $>$. Acesso em: 22 abr. 2011.

PATTO, M. H. S. A produção do fracasso escolar: história de submissão e rebeldia. São Paulo: Casa do Psicólogo, 2008.

PATTO, Maria Helena Souza; ANGELUCCI, Carla Biancha; KALMUS, Jaqueline; PAPARELLI, Renata. O estado da arte da pesquisa sobre o fracasso escolar (1991-2002): um estudo introdutório. Educação e Pesquisa [online], v. 30, p. 52-72, 2004. Disponível em: <http://www.scielo.br/pdf/ep/v30n1/ a04v30n1.pdf>. Acessado em: 2 jan. 2012.

RESENDE, Valéria Barbosa. Fracasso e sucesso escolar: os dois lados da moeda. In: GOMES, Maria de Fátima Cardoso; SENA, Maria das Graças de Castro (orgs.). Dificuldades de aprendizagem na alfabetização. Belo Horizonte: Autêntica, 2006.

SACRISTÁN, José Gimeno. A educação que ainda é possível: ensaios sobre uma cultura para a educação. Tradução de Valério Campos. Porto Alegre: Artmed, 2007.

SAMPAIO, Maria das Mercês Ferreira. Um gosto amargo da escola: relações entre currículo, ensino e fracasso escolar. São Paulo: Iglu, 2004.

SARMENTO, M. J. Sociologia da infância: correntes e confluências. In: GOUVEA, M. C. S.; SARMENTO, M. J. (orgs.). Estudos da Infância. Educação e Práticas Sociais. Rio de Janeiro: Vozes, 2009.

SAWAYA, Sandra Maria. Práticas de leitura e escrita entre as crianças na pobreza urbana. FEUSP, 2002. Disponível em: $<$ http://www.hottopos.com/videtur18/sandra.htm>. Acessado em: 4 abr. 2011.

SIRINO, Marisa de Fátima. Processos de exclusão intraescolar: os alunos que passam sem saber. São Paulo, 2009.230 p. Tese (Doutorado em Educação) - Universidade Estadual de Campinas, 2009.

SOLÉ, Isabel. Disponibilidade para aprendizagem e sentido da aprendizagem. In: COLL, César (orgs.). O Construtivismo na sala de aula. São Paulo: Ática, 2004.

SZYMANSKI, Heloisa. A entrevista na pesquisa em educação: a prática reflexiva. Brasília: Plano, 2002.

VYGOTSKY, L. S. (1987). Pensamento e linguagem. Tradução de José Cipolla Neto, Luís Silveira Menna Barreto e Solange Castro Afeche. São Paulo: Martins Fontes, 2007.

VYGOTSKY, L. S. A formação social da mente. Tradução de José Cippola Neto, Luís Silveira Menna Barreto, Solange Castro Afeche. São Paulo: Martins Fontes, 1999.

WEISZ, Telma. O diálogo entre o ensino e a aprendizagem. São Paulo: Ática, 2006

Submetido em: 13/05/2015

Aprovado em: 04/02/2016 